Produto \& Produção, vol. 17, n. 4, p. 62-79, dez. 2016

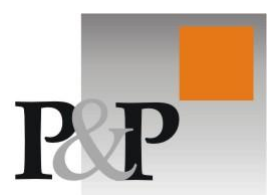

RECEBIDO EM 15/05/2016. ACEITO EM 11/10/2016.

\title{
Modelo de referência para o desenvolvimento de produtos mecânicos
}

\author{
Antonio Ventriglia Vieira \\ Universidade Federal de São Carlos - UFSCar \\ ventriglio@uol.com.br
}

\author{
Dra. Andréa Regina Martins Fontes \\ Universidade Federal de São Carlos - UFSCar \\ andreaf@dep.ufscar.br
}

\author{
Dr. Miguel Ángel Aires Borrás \\ Universidade Federal de São Carlos - UFSCar \\ maborras@ufscar.br
}

\author{
Dr. Cleyton Fernandes Ferrarini \\ Universidade Federal de São Carlos - UFSCar \\ cleyton@ufscar.br
}

\section{RESUMO}

A gestão do processo de desenvolvimento do produto (PDP) é vital para a competitividade e sobrevivência das organizações buscando a implementação de ferramentas que auxiliem a minimizar os custos e maximizar os resultados de produtividade. Este trabalho foi desenvolvido a partir de uma pesquisa-ação realizada em uma empresa multinacional alemã fabricante de redutores industriais e apresenta parte dos resultados contidos na dissertação de mestrado de Vieira (2016). O objetivo principal do artigo foi comparar as diferenças entre o modelo de PDP desenvolvido em um projeto de redutores planetários e o modelo de PDP anteriormente existente na empresa. Como principal resultado obteve-se a implantação de um modelo de PDP integrado e simultâneo com ganho de tempo de desenvolvimento e de manufatura (redução de $70 \%$ nos retrabalhos de desenhos e 50\% do tempo de projetos), minimizando os custos do equipamento em 7,5\%. Outro resultado dessa implementação foi a elaboração de um catálogo de redutores planetários modulares traduzido para cinco idiomas e distribuído em mais de treze países. Concluiu-se que a troca de modelo impactou positivamente na configuração das equipes de projeto, no paralelismo de atividades, na integração dos participantes e na possibilidade de utilizar ferramentas de apoio ao desenvolvimento de produtos durante o processo de projeto.

Palavras-chave: Desenvolvimento integrado de produtos; Engenharia simultânea; Redutores de velocidade planetários. 


\begin{abstract}
Managing the product development process (PDP) is vital for the competitiveness and survival of organizations seeking the implementation of tools that help to minimize costs and maximize the results of productivity. This work was developed from an action-research taken in a German multinational manufacturer of industrial gearboxes and presents some of the results included in the dissertation of Vieira (2016). The main result was the implementation of an integrated and simultaneous PDP model with development time and gain of manufacture (70\% reduction in rework designs and $50 \%$ of the project time), minimizing the cost of equipment at $7.5 \%$. Another result of this implementation was the elaboration of a modular planetary gearboxes catalogue translated into five languages and distributed in more than thirteen countries. It was concluded that the exchange model had a positive impact on the configuration of project teams, in parallel activities, the integration of the participants and the possibility of using tools to support product development during the design process.
\end{abstract}

Keywords: Development integrated products; Concurrent engineering; Planetary gearboxes.

\title{
1. Introdução
}

Atualmente o sucesso na gestão do sistema de desenvolvimento do produto é vital para a competitividade e sobrevivência das organizações, pois de acordo com Faria et al. (2008) a vantagem competitiva de uma empresa estaria diretamente ligada à sua capacidade de introduzir no mercado novos produtos com conteúdo tecnológico e características que atendam às exigências dos consumidores. Portanto, desenvolver produtos que atendam essas novas exigências ou que as antecipe constitui um ponto fundamental para a longevidade das empresas.

Segundo Takahashi e Takahashi (2007), o processo de desenvolvimento de produtos determina de 70 a $90 \%$ do custo final do produto, além de determinar o seu desempenho em qualidade e diversificação. Para os autores esse processo ainda traduz as ideias, objetivos e intenções em algo concreto, pelo qual os consumidores pagarão. Sendo assim, o processo de desenvolvimento de produtos (PDP) é um processo vital para a agregação de valor ao negócio.

Para uma empresa ser competitiva, é necessário a compreensão da estratégia empresarial para consolidação do produto no mercado e os pressupostos básicos, tais como, qualidade, custos e integração através da implementação do PDP. Os redutores planetários, foco do PDP descrito neste artigo, são utilizados quando se necessita de redução de velocidade e aumento de torque em espaços compactos. A terminologia "redutor de velocidade planetário" vem da semelhança do arranjo físico das engrenagens com o sistema solar. O pinhão sol está localizado no centro do mecanismo e está em contato com vários planetas que orbitam em torno dele. Os planetas são montados em um suporte denominado trem planetário que pode ser fixo ou rotativo.

Segundo Lynwander (1983), as transmissões mecânicas por engrenagens planetárias foram aplicadas na indústria em 1781, quando James Watt inventou um sistema composto por um pinhão sol e uma engrenagem planeta para uma de suas máquinas. Lanchester em 1895 ficou conhecido por ser o primeiro usuário de engrenagens planetárias em transmissões automotivas.

Na figura 1, é possível visualizar a representação esquemática de um conjunto de engrenagens planetárias composta pelo pinhão sol, pelas engrenagens planetas e pelo anel dentado. O trem planetário é uma estrutura relativamente rígida que tem a função de dar suporte às engrenagens planetas. 


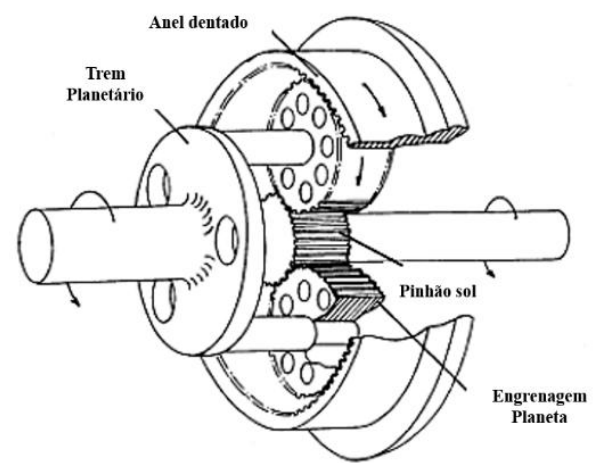

Figura 1 - Representação esquemática de um redutor planetário Fonte: adaptada de Lynwander (1983, p.147)

Diversas aplicações industriais necessitam que cargas pesadas sejam movimentadas de forma segura e confiável através de acionamentos mecânicos e elétricos. No que diz respeito ao processo de desenvolvimento de redutores planetários, ressalta-se que devido à quantidade e variedade de informações envolvidas em seu projeto torna-se crucial o uso de ferramentas que permitam gerenciar o processo de seu desenvolvimento.

Nesse contexto, o objetivo deste trabalho consiste em analisar o antigo modelo de PDP de uma empresa multinacional alemã fabricante de redutores industriais e compará-lo ao um novo modelo desenvolvido por meio de uma pesquisa-ação.

A estrutura do trabalho se apresenta da seguinte maneira: o próximo tópico apresenta a fundamentação teórica que embasou as discussões, o terceiro tópico apresenta o método de pesquisa utilizado, o quarto tópico apresenta os resultados obtidos, o quinto tópico apresenta as discussões e por fim o sexto tópico apresenta as considerações finais do artigo.

\section{Processo de Desenvolvimento do Produto e Modelos de Referência}

A excelência em desenvolvimento de produtos ocorre quando a empresa organiza adequadamente a estratégia, estrutura organizacional, sistematização das atividades, habilidades técnicas, abordagens para resolução de problemas e mecanismos de aprendizagem (CAMPOS; RIBEIRO, 2011).

Segundo Susman (1992), o envolvimento precoce na fabricação de um produto poderia reduzir o tempo desde a concepção de projeto até a entrega, pois potenciais problemas poderiam ser antecipados, evitando atrasos. Além disso, $80 \%$ dos custos de um produto são comprometidos nas atividades iniciais do projeto, sendo que o projeto compromete $70 \%$ dos custos do produto final. Esses valores reforçam a importância de se adotar práticas adequadas para o desenvolvimento do produto. Nesse sentido os autores Ogliari et al. (2008) destacam o PDP como um processo de grande relevância para as empresas.

Para Bórnia e Lorandi (2008) o projeto de um produto é um processo de múltiplas etapas, o PDP é o gerenciamento de como essas etapas devem ser estruturadas e operacionalizadas, de forma a tornar o processo eficiente e eficaz. Segundo os autores, o PDP não é uma atividade simples, pois exige esforço coordenado do trabalho de diversos setores ao longo do tempo.

Fazendo com que as atividades do PDP envolvem todo o ciclo de vida do produto e são embasadas no conceito de paralelo temporal de atividades (ROZENFELD et al., 2006). Para se beneficiar das vantagens multidisciplinares que o PDP oferece, uma empresa deve ter times de desenvolvimento de produtos compostos por profissionais qualificados nesta abordagem ao invés de profissionais que trabalhem isoladamente em funções específicas (MUNDIM et al., 2002). Segundo os autores, para formar esses times os profissionais devem combinar a expertise com a capacidade de trabalhar eficientemente em grupo, formando relacionamentos produtivos com clientes e fornecedores, além de refletir criticamente sobre as práticas organizacionais e se necessário transformá-las. 
Portanto, um PDP bem estruturado pode resultar em: redução no lead-time de desenvolvimento, repetibilidade dos projetos de desenvolvimento, maior racionalização no uso das informações, maior facilidade para treinar novas pessoas no processo e reutilização de conhecimentos gerados em outros projetos (AMARAL; ROZENFELD, 2008).

Segundo Davila (2000), o PDP é um processo incerto, e por essa razão é necessário que seja estruturado através de fases bem definidas, que terminem com a decisão sobre o futuro do projeto. Essas fases, segundo Paula e Mello (2013) representam o processo de negócio como um fluxo contínuo de atividades com entradas e saídas distintas que determinam o sucesso ou não do lançamento de um produto no mercado.

Com isso, as fases podem ser agrupadas em modelos de referência (AMARAL, 2006), que são, de acordo com Salgado et al. (2010), a união das melhores práticas relacionadas a um determinado processo de desenvolvimento, sendo estas representadas de forma clara para qualquer pessoa. Segundo os autores, seu objetivo é prover a empresa de uma base, a partir da qual ela pode definir um modelo de processo específico.

Desta maneira, construir um modelo de referência é realizar uma descrição mais abrangente possível de um determinado processo de negócio de forma que possa ser customizado para diferentes situações. $\mathrm{O}$ modelo deve agregar todas as atividades necessárias às diferentes instâncias do processo, as informações e recursos utilizados e a organização necessária para que sejam realizadas (AMARAL; ROZENFELD, 2008).

Salgado et al. (2010) ressaltam que como os modelos são interpretados e aplicados por seus usuários, cada um pode ser usado e aplicado de diferentes maneiras, dessa forma, a prática do desenvolvimento de produtos pode ser melhorada pela execução de novos modelos.

Para fins desta pesquisa, o conteúdo da revisão teórica deste artigo está relacionado a parte teórica da pesquisa-ação realizada na construção do novo modelo de PDP. Durante o processo de construção de conhecimento foram estudados quatro modelos de referência: modelo de Back (1983); o Total Design de Pugh (1991); o Stage-Gate de Cooper (1993) e o modelo unificado de Rozenfeld et al. (2006).

\subsection{Modelo de referência proposto por Back (1983)}

De acordo com o modelo proposto por Back em 1983, o projeto de um produto depois de iniciado se desdobra em uma sequência de eventos que seguem em ordem cronológica. Essa ordem sequencial das fases permite, segundo o autor, a transformação de recursos em objetivos proveitosos.

Back (2007) define o desenvolvimento do produto como um conceito amplo que compreende os aspectos de planejamento e projeto ao longo de todas as atividades do processo, desde a pesquisa de mercado até seu descarte. Além disso, o desenvolvimento integrado de produto considera todo o processo de transformação e geração de informações necessárias na identificação da demanda, na produção e no uso do produto. Para o sucesso desse procedimento é necessário que haja trabalho em equipe multidisciplinar desde o planejamento, e que os requisitos e restrições do produto sejam considerados ou pensados simultaneamente (BACK, 2007).

O modelo de referência proposto por Back (1983) é constituído por fases estruturadas para a criação de projeto de produtos, sendo uma de pré-desenvolvimento (estudo de viabilidade), três de desenvolvimento (projetos preliminar e detalhado, revisão e testes e planejamento para produção, mercado e consumo) e uma de pós-desenvolvimento (planejamento da obsolescência). Segundo Back e Ogliari (2000), na figura 2 observa-se que praticamente $80 \%$ dos custos do produto são comprometidos com os resultados das atividades iniciais do projeto (conceitual e preliminar) e que os efeitos das decisões tomadas nas fases iniciais do projeto podem comprometer o desempenho do produto ou do próprio empreendimento. 


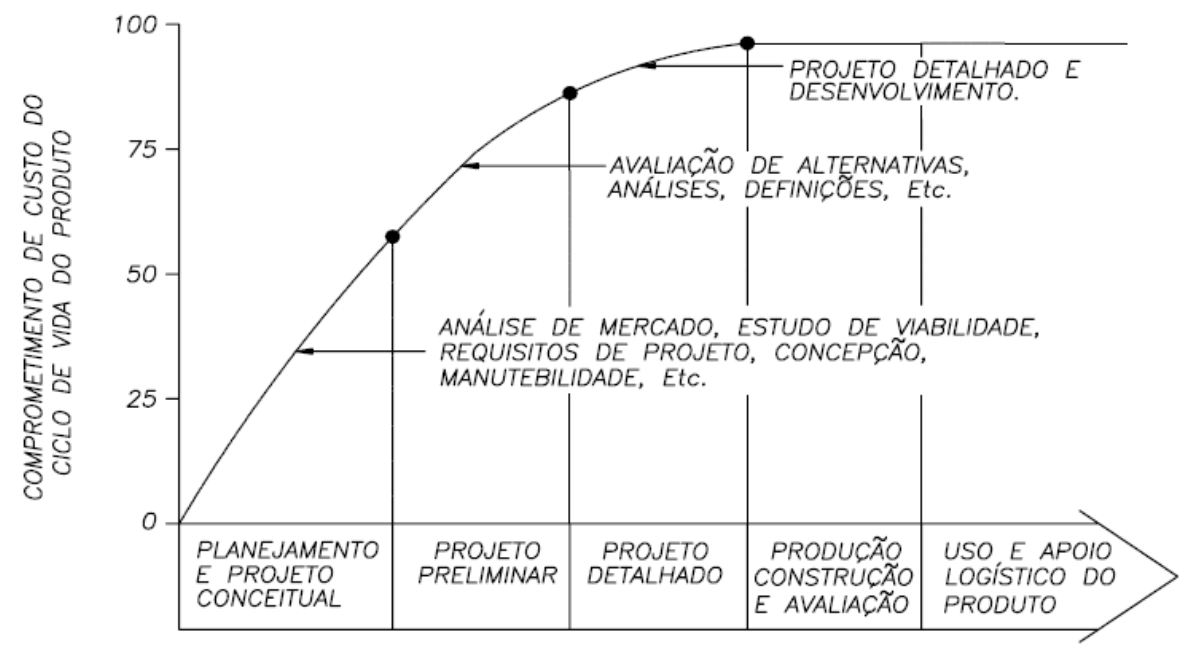

Figura 2 - Efeitos das diferentes fases do ciclo de vida sobre o custo do produto Fonte: Back e Ogliari (2000, p.03)

\subsection{Modelo Total Design de Pugh (1991)}

O modelo de gerenciamento de projetos Total Design está centrado diretamente no produto, pois sem ele, os negócios não existiriam. Assim, define-se o projeto total, sistematicamente, iniciando-o com a identificação da necessidade do mercado ou do cliente indo até a venda de um produto que compreenda a lacuna do mercado em relação a essa necessidade, anexando, também, as peculiaridades do processo, das pessoas e da organização (MELLO, 2005).

De acordo com Pugh (1996), o mercado quando satisfeito com o projeto, se ajustará ao mercado existente, ou criará um mercado a parte. Com a manifestação da necessidade, a especificação do projeto dará início à especificação do produto a ser gerido. Dessa forma, a especificação do projeto é como um manto, envolvendo os estágios restantes do projeto-núcleo. Logo, a especificação do projeto é uma forma de controlar, a partir dos limites estabelecidos pela especificação do projeto, as atividades subsequentes do projeto-núcleo (MELLO, 2011).

A partir do conceito de projeto-núcleo, Pugh (1996) desenvolveu uma matriz na qual se comparam projetos através de uma escala de avaliação. Um projeto convencional melhor pode ser usado como um dado em oposição no qual os novos projetos são comparados e enquanto o grupo completa a matriz avaliativa, isso faz com que novas ideias sejam geradas e, assim, adicionam-se novos conceitos sobre a matriz. Este processo repete-se muitas vezes até um conceito dentro da matriz emergir e não poder ser derrubado, isso é feito a partir da remoção dos elementos negativos da matriz (LUMSDAINE, 2006).

A relação mercado-vendas é definida como o fluxo principal do projeto e é, também, um processo interativo, pois um novo conceito pode aparecer mesmo depois de alcançado o projeto detalhado de um produto. Se este novo conceito for atrativo ao desenvolvimento do projeto e o tempo permitir, o desenvolvimento do projeto voltará para o estágio anterior até ser recriada a solução. Em todos os estágios da produção do produto há a interatividade da operação. Entretanto, em inspeções futuras, a sequencialidade dos estágios será mantida. Logo, qualquer ponto na atividade de projeto pode ser revertido, sempre sob o manto do projeto-núcleo, minimizando, assim, as alterações desnecessárias (MELLO, 2005). 


\subsection{Processo de Stage-Gate de Cooper (1993)}

Para Cooper (1993), o modelo seria uma proposta para conduzir o PDP ao sucesso através de avaliações em vários estágios de desenvolvimento, o número de estágios pode variar de quatro a seis. Após a execução das atividades de cada estágio há um portão (gate) que controla a qualidade do projeto. Os gates são sessões pontuais onde os resultados dos processos antes executados são avaliados e então ocorre a decisão dos responsáveis sobre seguir em frente ou não com o produto em questão. Na figura 3 está representado este processo resumidamente.

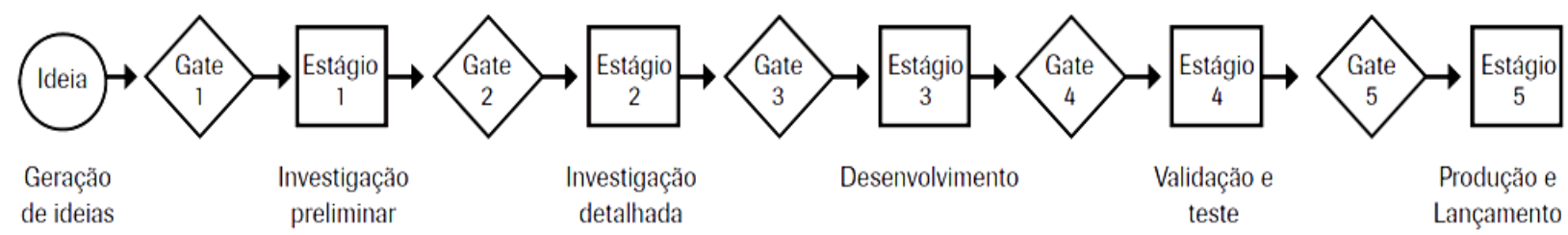

Figura 3 - O processo Stage-Gate genérico Fonte: Adaptado de Cooper (1993, p. 137).

Como pode ser visto na figura 3, o modelo compreende os seguintes estágios: investigação preliminar; investigação detalhada; desenvolvimento; validação e teste, e produção e lançamento, separados pelos gates que dividem o processo de desenvolvimento em estágios discretos e identificáveis (COOPER, 1993).

Em cada gate a continuidade do processo é decidida, geralmente, por um gerente. Essa decisão é baseada em informações disponíveis de acordo com o contexto histórico de cada época, por exemplo, o estado da economia, riscos de investimentos, entre outros fatores (SOUZA, 2012).

Quando bem aplicado, esse sistema de produção consegue obter resultados positivos quando se trata da descoberta de novos produtos e serviços para colocação no mercado de vendas, tudo isso com rapidez, eficiência e rentabilidade. A razão seria os menores ciclos de desenvolvimento criados pelo modelo e a maior integração multifuncional (MELLO et al., 2012).

É considerado um bom sistema de proteção a falhas e transtornos durante a fabricação de produtos, em virtude de sua estratégia de desenvolvimento de processos que incorporam variadas ferramentas em seu desenvolvimento, além de iniciativas para o desenvolvimento de novas mercadorias (MELLO et al., 2012).

\subsection{Modelo unificado de Rozenfeld (2006)}

O modelo unificado proposto por Rozenfeld et al. (2006), divide o PDP em três fases: prédesenvolvimento, desenvolvimento e pós-desenvolvimento. Nesse modelo, os recursos demandados e o tempo a serem executados nos processos são especificados como atividades dentro do processo e subdividem em fases as macro fases descritas, conforme ilustrado na figura 4 . 


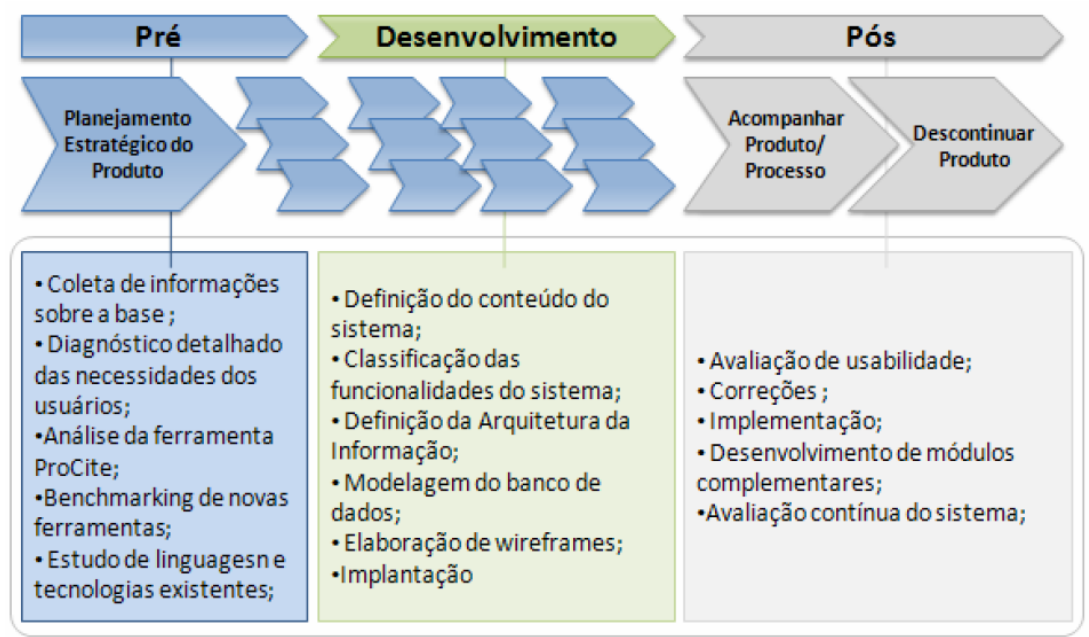

Figura 4 - Fases do desenvolvimento de Produtos

Fonte: Adaptado de Rozenfeld (BUFREM et al., 2010, p. 31)

Devido às dificuldades para prever detalhes críticos acerca dos fatores em relação aos produtos em desenvolvimento, Rozenfeld e Silva (2007) desenvolveram uma dimensão estratégica, com quatro perspectivas diferentes: gestão do portfólio de produtos, que se refere à coordenação estratégica dos projetos em andamento ou planejamento; a avaliação do desempenho, que é um trabalho de avaliação do PDP realizado, já pronto, a fim de destacar os pontos estratégicos mais relevantes para melhorias no método; condução das alianças e parcerias para o PDP, envolvendo a negociação da participação de seus fornecedores e clientes; e, a condução das relações interfuncionais e interdepartamentais, que visa a integração estratégica de marketing, engenharia e manufatura (ROZENFELD; SILVA, 2007).

Além da dimensão estratégica, Rozenfeld e Silva (2007) destacam mais três dimensões importantes ao PDP: a dimensão organização, que se refere às pessoas que estão desenvolvendo o PDP e suas localizações estratégicas; dimensão atividades/informações, onde se trata basicamente das atividades ao longo do processo de PDP, com significativos paralelismos, conforme suas especificidades e as informações manuseadas na execução das atividades; e a dimensão recursos, que dará importância aos métodos, técnicas, ferramentas e sistemas que tem a possibilidade de serem aplicados apoiando as dimensões anteriores (ROZENFELD; SILVA, 2007).

\section{Metodologia}

O método para condução e realização do presente trabalho é a pesquisa-ação, pois buscou analisar o ambiente de estudo e propor melhorias através da efetiva participação do autor deste trabalho, membro do corpo de engenharia de desenvolvimento de produtos e gestor do projeto de implantação de um modelo de PDP integrado e simultâneo.

Para Thiollent (2007), a pesquisa-ação é realizada dentro de uma organização na qual existe uma hierarquia ou cujos relacionamentos apresentam problemas, é ainda uma estratégia na engenharia de produção que visa produzir conhecimento e resolver um problema prático (MELLO et al., 2012).

De acordo com Mello et al. (2012) a combinação e uso de diferentes técnicas de coleta de dados favorece a validação da pesquisa. Nesta pesquisa foram utilizadas para triangulação de dados técnicas como: observação participante, entrevistas e análise documental e do ambiente da unidade estudada. $\mathrm{O}$ quadro 1 demonstra como cada uma das técnicas foi utilizada. 
Quadro 1 - Utilização das técnicas de coleta de dados

\begin{tabular}{|c|l|}
\hline Técnicas de coleta & \multicolumn{1}{c|}{ Utilização } \\
\hline $\begin{array}{c}\text { Análise } \\
\text { Documental }\end{array}$ & $\begin{array}{l}\text { Levantamento detalhado no sistema estudado, observando organogramas, descrição de } \\
\text { tarefas, fluxogramas, dados de produção e relatórios para o estudo da execução, } \\
\text { supervisão e direção. }\end{array}$ \\
\hline $\begin{array}{c}\text { Análise do } \\
\text { ambiente }\end{array}$ & $\begin{array}{l}\text { Análise profunda do cenário em que foi implementado o projeto que está sendo } \\
\text { apresentado }\end{array}$ \\
\hline $\begin{array}{l}\text { Observação } \\
\text { participante }\end{array}$ & $\begin{array}{l}\text { Reuniões de brainstorm com os envolvidos, registrando as informações em atas para } \\
\text { disponibilizar em consultas futuras. As reuniões caracterizaram-se por brainstorm, as } \\
\text { ideias foram anotadas para análise posterior e, caso necessário, validação da engenharia } \\
\text { de desenvolvimento reportando em ata as justificativas para utilização ou não de todas } \\
\text { as ideias }\end{array}$ \\
\hline \multirow{2}{*}{ Entrevista } & $\begin{array}{l}\text { Para saber a percepção dos envolvidos com o projeto sobre seus benefícios. } \\
\text { Os departamentos participantes para o levantamento e coleta dos dados foram: vendas; } \\
\text { engenharia de processos; manufatura; planejamento; montagem e assistência técnica. } \\
\text { Com o intuito de evitar conflitos de sugestões, cada departamento foi ouvido } \\
\text { separadamente, sem a influência de outras áreas. }\end{array}$ \\
\hline
\end{tabular}

Fonte: Vieira (2016, p.54)

A análise dos dados da pesquisa-ação envolve a tabulação dos dados, comparação dos dados empíricos com a teoria e elaborar plano de ação (MELLO et al., 2012).

\section{Resultados}

A empresa analisada não possuía um modelo para elaboração dos projetos de redutores de velocidade. O desenvolvimento do projeto era feito de forma linear, ou seja, cada etapa do projeto era iniciada após a finalização da etapa anterior, as decisões eram tomadas de forma individual e independente dos demais departamentos da empresa.

Além disso, o processo era controlado por revisões formais ao fim de cada atividade, não contemplando características do contexto industrial, como por exemplo: o ambiente, a linguagem, a formação dos projetistas, entre outros.

Nesse formato, o projeto não ocorria com o compartilhamento de conhecimentos para desenvolver o produto, baseava-se principalmente nas habilidades individuais dos projetistas. O responsável pelo projeto trabalhava de forma individualizada, centralizando todas as informações e tecnologias adotadas no projeto. A identificação das alterações necessárias no projeto ocorria de forma tardia, em meio aos processos gerando perda de tempo hábil. Havia também o excesso de retrabalho de projetos, pois se buscava a utilização de ferramentas existentes na manufatura a fim de reduzir investimentos na compra de novas ferramentas e dispositivos.

Outros problemas relacionados à elaboração sequencial dos projetos eram: peças exclusivas para o equipamento vendido (exigindo investimentos em ferramentas e dispositivos de montagem exclusivos); excesso de retrabalhos em desenhos liberados para a fabricação e montagem; maior número de compradores dedicados a um equipamento especifico; estoque de peças dedicadas a um único produto; necessidade de grande área para estocagem e armazenamento de peças brutas e acabadas; lead time de projeto muito alto (produtos únicos); necessidade de mão-de-obra especializada para o desenvolvimento dos projetos; falta de padronização em desenhos; e, falta de um catálogo para facilitar a comercialização dos equipamentos que eram configurados de acordo com a necessidade do cliente.

A empresa possuía redutores planetários em seu portfólio de produtos desenvolvidos de forma customizada, atendendo as necessidades especificas dos clientes. As características de customização prejudicavam a negociação e seleção dos equipamentos de forma ágil, sendo necessária a intervenção rotineira da engenharia de desenvolvimento junto ao departamento de vendas. Em algumas ocasiões, a 
análise e a resposta não eram imediatas e o vendedor era obrigado a abrir uma solicitação de consulta para o departamento de desenvolvimento de produtos.

A necessidade de elaboração de um catálogo de redutores planetários padronizados que facilitasse e fornecesse autonomia para os vendedores externos foi um fator preponderante para a percepção da necessidade de mudança e adoção de um modelo de PDP. A adoção de um modelo de PDP ocorreu de forma planejada e organizada com o apoio total da diretoria e gerência da empresa e foi elaborado conforme as seguintes etapas: seleção de um responsável para gerenciamento; mapeamento do modelo utilizado anteriormente; seleção de um modelo de PDP; formação da equipe multidisciplinar; reuniões para elaboração do conceito do produto; elaboração e apresentação do conceito do produto; fabricação e análise do protótipo; validação e replicação do projeto para a série de produtos e lançamento do catálogo.

A seleção do responsável para o desenvolvimento do projeto do redutor planetário foi feita pela diretoria e pela gerencia da área de desenvolvimento de produtos e engenharia industrial. $\mathrm{O}$ critério para seleção do responsável foi o tempo de experiência e maturidade no desenvolvimento de projetos de redutores planetários. Foi selecionado para o gerenciamento do desenvolvimento de um novo produto e pela implantação de um novo modelo de PDP o engenheiro de pesquisa e desenvolvimento, autor deste artigo, que deveria propor um produto otimizado, com um lead time de projeto e fabricação menores que os usuais e que atendesse as necessidades de modularidade dos clientes internos e externos.

$\mathrm{O}$ desenvolvimento dos produtos vendidos era feito por um especialista selecionado pelo supervisor da área, para a escolha do especialista era considerada sua experiência na elaboração de projeto de cada tipo de produto. As atividades realizadas pelo especialista para desenvolver os produtos antes da adoção de um modelo de PDP seguem apresentadas na figura 5.

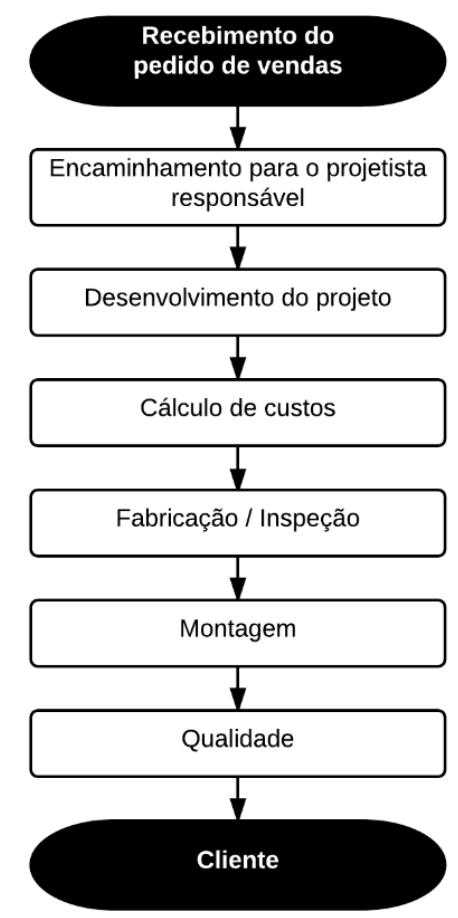

Figura 5 - Fluxograma antes da adoção de um modelo de PDP Fonte: Vieira (2016, p.61)

Em nenhum momento existia a aprovação do projeto por parte de uma equipe ou por pessoas de outros departamentos da empresa. Todas as tarefas eram de responsabilidade de uma única pessoa, dificultando a rastreabilidade e o histórico dos eventos na ausência do responsável pelo projeto, 
comprovando necessidade de pesquisa e adoção de um modelo de PDP para desenvolvimento de uma série de redutores planetários modulares.

\subsection{Seleção de um novo modelo de PDP}

A empresa analisada foi fundada em 1931 na Alemanha e atualmente é líder no mercado mundial de redutores de velocidade. Está presente em 48 países e possui 15 fábricas instaladas em países como França, Finlândia, Estados Unidos, Rússia, China e Brasil. Sua estrutura ainda inclui 79 montadoras localizadas em vários pontos do mundo. O grupo emprega mais de 16.000 funcionários e fatura globalmente mais de 2,6 bilhões de euros por ano. A empresa no Brasil, unidade na qual ocorreu a pesquisa, possui um amplo portfólio de produtos e serviços, incluindo os redutores de velocidade planetários modulares, para utilização em regime de trabalho pesado nas indústrias de mineração, agroindústria, processamento de madeira, entre outras.

A seleção do modelo de PDP ocorreu após análise e pesquisa dos modelos de referência levantados na revisão teórica buscando atender a integração dos departamentos envolvidos diretamente com o produto e a modularidade das peças.

Foi então criado um fluxograma de atividades para o desenvolvimento dos redutores planetários modulares que atendesse as necessidades de integração dos diversos departamentos da empresa envolvidos com o produto e também que considerasse a validação do projeto por uma equipe multifuncional. Além disso, foi incluída a análise dos custos dos equipamentos, com isso, seria possível saber o custo do equipamento antes da fabricação. Na figura 6 são apresentadas as atividades propostas para o novo modelo de PDP da empresa. 


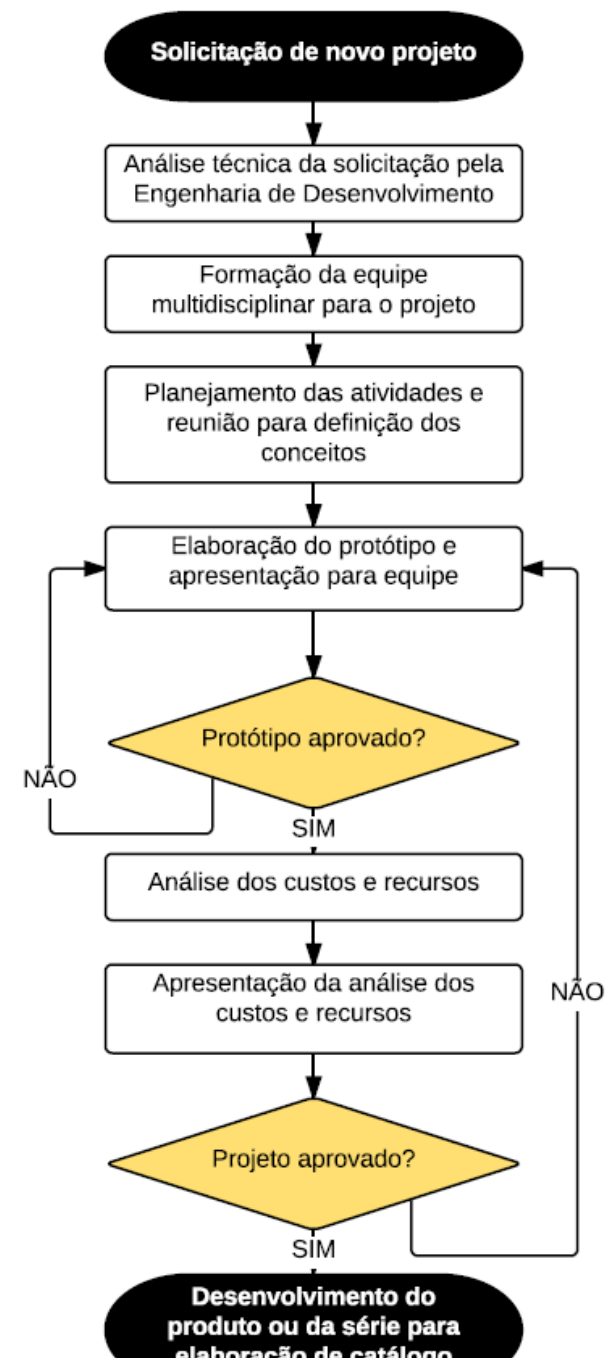

Figura 6 - Fluxograma após estudo dos modelos de PDP Fonte: Vieira (2016, p.63)

Para atender as demandas de um projeto integrado e atingir diferentes setores foi montada uma equipe multidisciplinar. Para a formação da equipe foram consideradas as competências individuais necessárias para o desenvolvimento do projeto. Por meio do mapeamento das atividades e do processo de desenvolvimento do produto, foi possível identificar os departamentos essenciais para compor o grupo: vendas e marketing, engenharia de desenvolvimento de produtos, engenharia de processos de fabricação, departamento de manufatura, qualidade, montagem e assistência técnica.

O convite para participação da equipe multidisciplinar foi feito pelo gestor do projeto através da solicitação de uma reunião com os gestores dos departamentos citados. Nesta reunião foram detalhados os objetivos e as metas do projeto e foi solicitado aos gestores que selecionassem colaboradores com maior experiência para contribuir com ideias para o desenvolvimento do novo produto e participarem de reuniões posteriores.

As reuniões eram administradas pelo gestor do projeto e agendadas conforme as necessidades do desenvolvimento do projeto. A ideia principal era debater em equipe os problemas encontrados com o produto conhecido e as sugestões para elaboração do novo conceito.

Para evitar discussões sobre incompatibilidade de ideias para o desenvolvimento do produto entre os diversos departamentos da equipe multifuncional, as reuniões durante a fase de geração dos conceitos foram divididas em dois grupos: 1) vendas e marketing, montagem e assistência técnica; 2) engenharia de 
desenvolvimento, engenharia de processos de usinagem, manufatura e qualidade. A gestão das incompatibilidades foi analisada pelo gestor do projeto e posteriormente exposta nas reuniões para toda a equipe.

A primeira reunião, um brainstorm, serviu para expor os problemas observados durante a fabricação, montagem e assistência técnica dos redutores planetários anteriores, e também para captação das ideias para otimização do novo produto. Nas reuniões com cada equipe estavam presentes os representantes de cada departamento, geralmente gerente, supervisor e engenheiro sênior ou pessoa de mais experiência do departamento. Sabendo do assunto, nada impedia que os gestores de departamento se reunissem com sua equipe para a captação dos problemas e sugestões de melhoria.

$\mathrm{O}$ gerente do projeto e a engenharia de desenvolvimento de produtos foram os responsáveis pelas anotações dos problemas e sugestões dadas para a elaboração do conceito do novo produto. O documento com o registro de consertos em garantia do período de março de 2010 a setembro de 2012 foi utilizado como suporte para a reunião, pois neste documento era possível verificar as possíveis melhorias do produto no ponto de vista do cliente externo. Todas as sugestões foram registradas, analisadas posteriormente e respondidas em ata de reunião comentada que foi distribuída para todos os participantes.

\subsubsection{Elaboração e apresentação do conceito}

Um projeto piloto aplicando as sugestões dadas pela equipe multifuncional foi modelado no software SolidWorks 2012 da empresa Dassault e apresentado para as equipes para que fosse validado o conceito. Depois de aprovado pelas equipes foi solicitada ao departamento de custos a comparação dos custos de fabricação entre o novo conceito e anterior, comprovando que os custos de fabricação do projeto piloto desenvolvido eram menores que os do projeto anterior.

Foi então agendada uma reunião de toda equipe com a diretoria e gerência da empresa para a apresentação do conceito do produto. Nesta reunião foi salientada a importância da equipe no desenvolvimento do produto, pois o conceito foi criado e validado através da cooperação e das sugestões de todos os departamentos envolvidos.

Após reunião, a diretoria e gerência da empresa definiram a fabricação de um protótipo para análise prática das alterações sugeridas e para a validação dos conceitos aplicados. A figura 7 ilustra o projeto do redutor planetário antes e depois da aplicação das sugestões dadas pela equipe multidisciplinar.

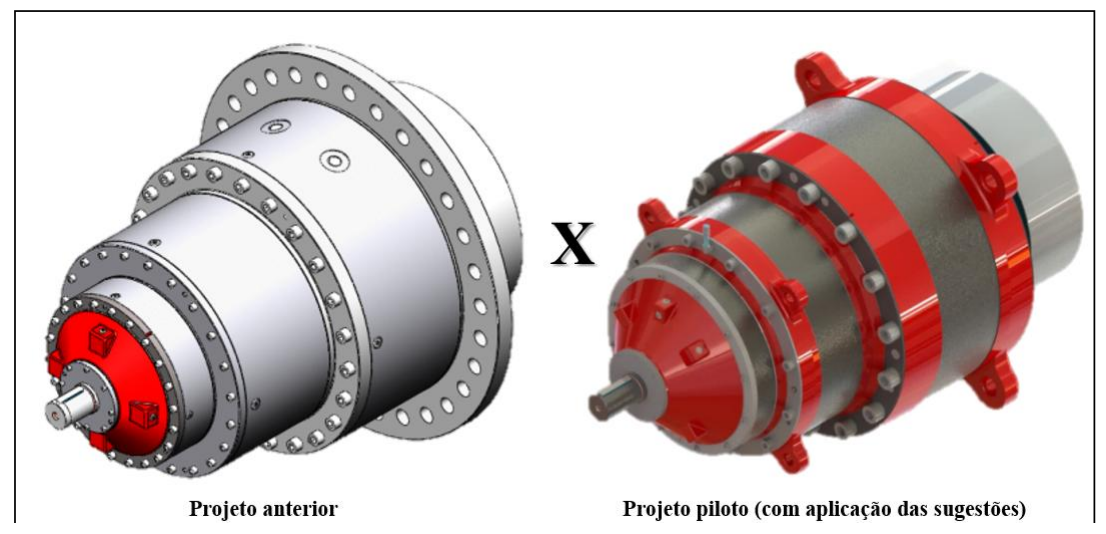

Figura 7 - Comparação dos projetos

Fonte: Vieira (2016, p.68)

Com a elaboração do projeto integrado e modular foi possível reduzir $14 \%$ a quantidade de parafusos e $57 \%$ a quantidade de modelos de fundição necessários para fabricação dos flanges e trens 
planetários. Outra observação interessante é a elaboração de suportes para facilitar a movimentação dos equipamentos.

\subsubsection{Fabricação e Análise do protótipo}

A partir da modelagem dimensional e do detalhamento das peças do equipamento definidos no projeto piloto foi possível a fabricação completa de um redutor planetário no novo conceito modular e integrado.

Durante a fabricação, a equipe se reunia semanalmente para acompanhar a percepção prática das sugestões aplicadas. A fabricação foi acompanhada pelos envolvidos desde a aquisição da matéria-prima até a montagem final do equipamento, evidenciando a cooperação e o apoio da equipe em todas as fases.

Após a montagem do equipamento foi feita uma reunião com toda a equipe para a análise dos processos de fabricação e montagem para relatar as facilidades e os problemas encontrados durante $o$ processo de manufatura, permitindo assim ajustes do projeto piloto para replicação nos demais equipamentos que iriam compor o catálogo.

Para a replicação do projeto piloto e elaboração de uma série completa de equipamentos planetários modulares, a engenharia de desenvolvimento fez um benchmark com ajuda do departamento de vendas e marketing, com intuito de definir os melhores torques e relações de transmissão para os equipamentos. Após essa definição a engenharia ficou responsável por replicar todos os conceitos adotados nos demais equipamentos, sendo possível o desenvolvimento de uma série completa com treze tamanhos de redutores planetários diferentes. Durante o desenvolvimento da série, a variação dos tamanhos permitiu o desenvolvimento de equipamentos de 4 até 35 toneladas de massa.

Depois de desenvolvida a série foi possível a elaboração de um catálogo físico e digital de produtos para clientes e vendedores. Neste catálogo é possível encontrar todas as informações dimensionais e técnicas, facilitando a divulgação e seleção dos equipamentos.

O conceito integrado e modular aplicado no desenvolvimento chamou a atenção da matriz da empresa na Alemanha e o catálogo foi traduzido para cinco idiomas e distribuído em mais de treze países da Europa, Ásia e continente Americano.

\section{Discussão: comparação entre os modelos Atual e Anterior}

O quadro 2 apresenta a comparação entre o novo modelo de PDP e o antigo. 
Quadro 2 - Comparação entre os modelos atual x anterior

\begin{tabular}{|c|c|c|c|c|}
\hline Caracteristicas & & Modelo Atual (Novo) & & Modelo Anterior (Antigo) \\
\hline Custo do produto & $\hat{\imath}$ & $\begin{array}{l}\text { - Facilitou a aquisição de matéria-prima e itens } \\
\text { padronizados (rolamentos, parafusos, arruelas ....). A } \\
\text { aquisição pode ser feita em lotes maiores } \\
\text { possibilitando a redução do preço de aquisição. } \\
\text { - Possibilitou o aumento dos lotes de fabricação e } \\
\text { consequentemente o reaproveitamento de setup das } \\
\text { máquinas. }\end{array}$ & $\downarrow$ & $\begin{array}{l}\text { - Aquisição de matéria-prima e itens padronizados } \\
\text { em quantidades muito pequenas. } \\
\text { - O tempo de setup das máquinas era diluído apenas } \\
\text { na manufatura de um único item. }\end{array}$ \\
\hline $\begin{array}{c}\text { Integração do projeto e dos } \\
\text { departamentos }\end{array}$ & $\hat{\imath}$ & $\begin{array}{l}\text { - O desenvolvimento e a aprovação do conceito foi } \\
\text { feito por uma equipe multifuncional. } \\
\text { - Aproveitamento de ferramentas e dispositivos } \\
\text { existentes. }\end{array}$ & $\downarrow$ & $\begin{array}{l}\text { - O projeto seguia a característica sequencial e era } \\
\text { desenvolvido através da experiência de uma única } \\
\text { pessoa. } \\
\text { - Necessidade de retrabalho em desenhos por não } \\
\text { haver dispositivos e ferramentas para manufatura das } \\
\text { peças. }\end{array}$ \\
\hline Padronização & 个 & $\begin{array}{l}\text { - Possibilidade de padronização no desenvolvimento. } \\
\text { - Facilitou a fabricação e montagem dos } \\
\text { equipamentos. }\end{array}$ & $\checkmark$ & $\begin{array}{l}\text { - Cada projeto saia de acordo com a experiência do } \\
\text { projetista que estava desenvolvendo. }\end{array}$ \\
\hline Tempo de projeto & $\downarrow$ & $\begin{array}{l}\text { - O projeto foi pensado como uma série de produtos } \\
\text { e não como um projeto isolado. Para conclusão do } \\
\text { projeto foi necessário o desenvolvimento da série de } \\
\text { produtos. }\end{array}$ & $\hat{\imath}$ & $\begin{array}{l}\text { - O projeto é feito de forma isolada sem o } \\
\text { reaproveitamento de peças de outros projetos. O } \\
\text { tempo gasto para o projeto era o tempo necessário } \\
\text { para um único desenvolvimento. }\end{array}$ \\
\hline Legenda & $\hat{\imath}$ & Melhor & 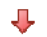 & Pior \\
\hline
\end{tabular}

Fonte: Vieira (2016, p.71)

No sistema anterior, após o recebimento de cada ordem de venda, o projetista responsável desenvolvia o equipamento conforme as necessidades específicas do cliente, elaborando uma lista de peças (itens comprados ou fabricados) que era enviada para o departamento de planejamento da produção para elaboração das ordens de fabricação ou para solicitação de compras. Com a ordem de fabricação em mãos, o departamento de engenharia de processos era responsável pela seleção das ferramentas de manufatura e pela elaboração dos programas CNC. Todas essas tarefas eram repetidas conforme as ordens de venda, fazendo com que houvesse a repetição de tarefas.

No modelo atual, o vendedor seleciona o equipamento conforme as necessidades dos clientes e as características dimensionais do catálogo. Elaborada a ordem de venda, a lista de peças, as ordens de fabricação e solicitações de compras dos itens padronizados são geradas automaticamente. A modularidade das peças faz com que todos os departamentos envolvidos com o produto passem a se preocupar com o gerenciamento das atividades e não com a elaboração das mesmas.

A respeito da redução de custos de fabricação obtidos com a integração e modularidade o resultado foi uma redução de 7,5\% quando comparado com o equipamento desenvolvido de forma sequencial. Além disso, a engenharia de desenvolvimento adquiriu segurança no processo de desenvolvimento integrado para a finalização do projeto e elaboração da linha completa de redutores planetários modulares. Também foi percebida a redução de $70 \%$ nos retrabalhos de desenhos elaborados para a manufatura e a redução de $50 \%$ do tempo de desenvolvimento de novos projetos, estes valores foram obtidos através do apontamento das atividades dos engenheiros e projetistas do departamento de desenvolvimento de produtos.

O projeto demorou cerca de dezoito meses para ser concluído devido as prioridades da alta gerência, durante esse período alguns fatores foram considerados desafiadores. O quadro 3 apresenta os principais desafios encontrados na implantação do novo modelo, como foram diagnosticados e as soluções adotadas. 
Quadro 3 - Desafios encontrados na fase de transição

\begin{tabular}{|c|c|c|}
\hline Desafios & Como foi diagnosticado & Solução \\
\hline $\begin{array}{c}\text { Falta de objetivos } \\
\text { e metas }\end{array}$ & $\begin{array}{l}\text { - Existia apenas a necessidade de mudança do produto, } \\
\text { porém sem objetivos claramente definidos. }\end{array}$ & $\begin{array}{l}\text { - Foi necessário estabelecer os indices de desempenho, o } \\
\text { tempo de desenvolvimento, e determinar com clareza os } \\
\text { objetivos almejados. } \\
\text { - Foi elaborado um cronograma de atividades e o mesmo } \\
\text { foi gerenciado pelo gestor da implantação no novo } \\
\text { modelo. }\end{array}$ \\
\hline $\begin{array}{l}\text { Falta de } \\
\text { experiência da } \\
\text { equipe }\end{array}$ & $\begin{array}{l}\text { - A equipe não conhecia o conceito de modularidade e de } \\
\text { engenharia simultânea. } \\
\text { - Pensou-se na busca de especialistas externos para } \\
\text { ajudar, mas esses individuos não possuiam } \\
\text { conhecimentos quanto às práticas da organização. }\end{array}$ & $\begin{array}{l}\text { - Ressaltou-se a importância e valorização do } \\
\text { conhecimento sobre a organização. } \\
\text { - Foram estabelecidos mecanismos para o aprendizado, } \\
\text { como a revisão, análise e avaliação dos conceitos e } \\
\text { atividades. }\end{array}$ \\
\hline $\begin{array}{l}\text { Cooperação } \\
\text { funcional }\end{array}$ & $\begin{array}{l}\text { - Para tornar o processo integrado, a equipe } \\
\text { multifuncional deveria ter representantes de todas as } \\
\text { áreas da empresa. }\end{array}$ & $\begin{array}{l}\text { - Um dos membros da alta gerencia, agendou uma } \\
\text { reunião para esclarecer as razões pelas quais o novo } \\
\text { modelo era necessário, assim como estabeleceu o método } \\
\text { de operação da equipe, delegando a gestão do projeto para } \\
\text { um responsável. }\end{array}$ \\
\hline Paralisia cultural & $\begin{array}{l}\text { - Foi um dos desafios mais complicados, já que as } \\
\text { pessoas rejeitam rápida ou veementemente novas ideias e } \\
\text { é necessário mudar a cultura dentro da organização. }\end{array}$ & $\begin{array}{l}\text { - Para alterar a cultura da empresa, buscou-se mudar a } \\
\text { cultura individual e a valorização de todas as ideias na } \\
\text { fase de geração de conceitos. Todos as ideias foram } \\
\text { ouvidas e analisadas, fazendo com que todos os membros } \\
\text { da equipe se sentissem importante e donos do projeto. }\end{array}$ \\
\hline $\begin{array}{l}\text { Variedade de } \\
\text { modelos de PDP }\end{array}$ & $\begin{array}{l}\text { - Em função da variedade imensa de modelos de PDP } \\
\text { existente, seria necessário focar em alguma caracteristica } \\
\text { fundamental para o novo processo. }\end{array}$ & $\begin{array}{l}\text { - Para a seleção do novo modelo foram analisados os } \\
\text { modelos de PDP de } 07 \text { autores com foco na engenharia } \\
\text { simultânea e desenvolvimento integrado. }\end{array}$ \\
\hline $\begin{array}{l}\text { Implantação do } \\
\text { modelo }\end{array}$ & $\begin{array}{l}\text { - Necessidade de adoção de um modelo integrado e do } \\
\text { desenvolvimento de um projeto modular. }\end{array}$ & $\begin{array}{l}\text { - O projeto de implantação deve ser lançado como um } \\
\text { evento cujo planejamento e execução são fundamentais, } \\
\text { caso contrário, não ocorre o entendimento de todos. Para } \\
\text { tanto, precisa-se do apoio da alta gestão da organização. }\end{array}$ \\
\hline Medo do insucesso & $\begin{array}{l}\text { - Falta de experiência na aplicação de um modelo de PDP } \\
\text { e a necessidade de lançamento do produto em uma data } \\
\text { definida pela alta gestão. }\end{array}$ & $\begin{array}{l}\text { - Esse temor em relação ao erro pode ser superado } \\
\text { através da conscientização de que eles acontecem e } \\
\text { podem oferecer uma rica fonte de aprendizado, desde que } \\
\text { abertamente discutidos. }\end{array}$ \\
\hline $\begin{array}{l}\text { Especificações do } \\
\text { projeto }\end{array}$ & $\begin{array}{l}\text { - Desenvolver um equipamento com especificações que } \\
\text { atendam todas as necessidades dos clientes internos e } \\
\text { externos. }\end{array}$ & $\begin{array}{l}\text { - Para minimizar a ocorrência de problemas, as } \\
\text { especificações do projeto devem ser estabelecidas pela } \\
\text { equipe de desenvolvimento, em vez de impostas à equipe. }\end{array}$ \\
\hline $\begin{array}{l}\text { Lançamento do } \\
\text { catálogo }\end{array}$ & $\begin{array}{l}\text { - Necessidade de um catálogo fisico e eletrônico para dar } \\
\text { autonomia para os vendedores e clientes. }\end{array}$ & $\begin{array}{l}\text { - O projeto de implantação deve ser lançado como um } \\
\text { evento cujo planejamento e execução são fundamentais, } \\
\text { caso contrário, não ocorre o entendimento de todos. Para } \\
\text { tanto, precisa-se do apoio da alta gestão da organização. }\end{array}$ \\
\hline $\begin{array}{l}\text { Expansão e } \\
\text { validação do } \\
\text { modelo adotado }\end{array}$ & $\begin{array}{l}\text { - Validação e expansão do modelo de PDP afim de tornar } \\
\text { o lançamento do produto mundial e não apenas para o } \\
\text { marmadn hrasileirn }\end{array}$ & $\begin{array}{l}\text { - O produto foi apresentado para o departamento de } \\
\text { vendas da Alemanha e uma equipe de engenheiros veio ao } \\
\text { Rrasil nars validarãn An nrniatn a dn mndeln adnts }\end{array}$ \\
\hline
\end{tabular}

Fonte: Vieira (2016, p.75)

\section{Considerações Finais}

A realização da presente investigação foi motivada pela necessidade de compreender como se dá o processo integrado dos produtos e a adoção do modelo simultâneo de projeto, avaliando os resultados dessa prática, e se de fato é possível obter diferenciais positivos dentro de um projeto de redutores de velocidade planetários modulares.

No modelo anterior havia uma dependência entre as etapas do projeto, caracterizado como engenharia sequencial, onde a engenharia de desenvolvimento era o único departamento responsável pelos processos de execução e validação dos projetos. Os clientes internos e externos não podiam optar no projeto, não havia troca de experiências ou de informações, gerando perda de tempo devido retrabalho de desenhos e execução de tarefas repetitivas além do aumento dos riscos de falhas.

Durante o período de transição do modelo antigo para o atual ocorreram algumas dificuldades, como: a falta de objetivos ou de experiência por parte da equipe (desnivelamento multidisciplinar); necessidade de administrar a paralisia cultural da organização (saber lidar com o medo do insucesso do 
projeto). É importante ressaltar que situações externas também foram desafiadoras, como por exemplo, a dificuldade em vencer as barreiras do subdesenvolvimento, pois este projeto foi o primeiro de grande porte elaborado pela equipe de engenharia de desenvolvimento da empresa no Brasil.

Para desenvolver o planejamento de modificações e implantação do novo modelo, a teoria foi fundamental para fornecer apoio e base para que o novo modelo pudesse ser adaptado às condições reais e práticas da organização. A pesquisa bibliográfica e as trocas de informações com funcionários de diversas áreas foram essenciais para adotar a teoria de projeto integrado como novo modelo dentro da organização. Para o planejamento efetivo da implementação desse projeto, reconheceu-se a importância do apoio da alta gerência e diretoria da empresa, que autorizaram a engenharia a tornar-se responsável pelo desenvolvimento do projeto e implantação do modelo de desenvolvimento de produtos.

Como principal resultado, obteve-se a implantação de um modelo de PDP integrado e simultâneo com ganho de tempo de desenvolvimento e de manufatura, resultando na diminuição dos custos do equipamento, a partir da redução do número de itens (facilitando a armazenagem e planejamento da produção); da redução do número de dispositivos e ferramentas de usinagem e fundição; da padronização do trabalho e desenhos (eliminando os serviços repetitivos ou duplicados) e da redução do tempo de projeto e fabricação.

A implantação foi necessária para atender às necessidades tanto dos clientes internos quanto externos. Através dessa implementação foi possível a elaboração de um catálogo de distribuição mundial de redutores planetários

Os aspectos de melhoria foram possíveis a partir das ideias geradas pela equipe multifuncional durante o brainstorm de coleta de informações para desenvolvimento do novo conceito dos redutores planetários modulares. A integração entre os membros da equipe proporcionou a troca de conhecimentos e experiências, gerando maior empenho dos envolvidos.

Por fim, os resultados ficaram de acordo com o esperado desde o início da execução do estudo, isto é, foram identificados benefícios nas modificações realizadas na maneira como a engenharia vinha trabalhando e nas modificações aplicadas ao produto com a modularidade e integração de todo o projeto. A pesquisa-ação contribuiu facilitando os procedimentos de pesquisa, aplicação e validação do estudo onde foram enxergados diversos modelos de desenvolvimento de produtos.

Como sugestão de trabalho futuros, a confecção de um protótipo de sistema abre a possibilidade da complementação do trabalho, através outros estudos mais completos com o maior envolvimento de conhecimentos das diversas áreas que acompanham o processo de desenvolvimento do produto, ou seja, comparar o método aplicado com os métodos existentes, avaliando os pontos positivos e negativos e assim aperfeiçoá-los.

\section{Referências}

AMARAL, C. D. et al. Gestão de Desenvolvimento de Produtos - Uma referência para a melhoria do processo. ed. São Paulo: Saraiva, 2006, 541 p.

AMARAL, C. D.; ROZENFELD, H. Sistematização das melhores práticas de desenvolvimento de produtos para acesso livre e compartilhado na internet. Produto \& Produção, v. 9, n. 2, p. 120-135, 2008 .

ASIEDU, Y.; GU, P. Product life cycle cost analysis: state of the art review. International journal of production research, v. 36, n. 4, p. 883-908, 1998.

BACK, N. Metodologia de Projeto de Produtos Industriais. Rio de Janeiro: Guanabara Dois, 1983. 92 p. 
BACK, N. Capacitação em Desenvolvimento Integrado de Produtos - Departamento de Engenharia Mecânica Universidade Federal de Santa Catarina- 2007. 133 p.

BORNIA, A. C.; LORANDI, J. A. O processo de desenvolvimento de produtos compartilhado na cadeia de suprimentos. Revista FAE, v. 01, n. 02, p. 35-50, 2008

BUFREM, L. S. et al. Modelizando práticas para a socialização de informações: a construção de saberes no ensino superior. Perspect. ciênc. inf., Belo Horizonte, v. 15, n. 2, p. 22-41, Aug. 2010 .

CAMPOS, S. U.; RIBEIRO, J. L. D. Um modelo de referência para o processo de desenvolvimento de produtos de empresas do setor moageiro de trigo. Produção, v. 21, n. 3, p. 379-391, 2011.

COOPER, R. G. Winning at New Products: accelerating the process from idea to launch. 2 ed. Reading: Addison-Wesley Publishing, 1993, 425 p.

COUGHLAN, P; COUGHLAN, D. Action Research for operations management. International Journal of Operation and Production Management, v.22, n.2, p.220-240, 2002.

DAVILA, T. An empirical study on the drivers of management control systems design in new product development. Account, Organization end Society, v. 125, p. 383-409, 2000.

FARIA, A. F et al. Processo de desenvolvimento de novos produtos. In: Enegep, 28, 2008. Anais... Rio de Janeiro, 2008.

LUMSDAINE, M.; LUMSDAINE, E.; Pugh method example: design of a car horn. 2006. Disponível em <https://pt.scribd.com/doc/234366232/Pugh-Method-Example> Acesso em maio/2015.

MELLO, C.H.P. et al. Modelo para projeto e desenvolvimento de serviços. 2005. Tese (Doutorado em Engenharia). Universidade de São Paulo, São Paulo. 2005.

MELLO, C. H. P. et al. Pesquisa-ação na engenharia de produção: proposta de estruturação para sua condução. Produção, v.22, n. 1, p.1-13, 2012.

MELlO, E. B. Processo de Desenvolvimento de produtos e o sistema Stage-Gate. Gestão Contemporânea, Porto Alegre, edição especial, 2012.

MELLO, W. B. Proposta de um método aberto de projeto de produto: três alternativas de criação. Tese (Mestrado em Engenharia). Universidade de São Paulo, São Paulo. 2011.

MUNDIM, A. P. F. Aplicando o cenário de Desenvolvimento de Produtos em um caso Prático de Capacitação Profissional. Gestão e Produção, v. 9, n. 1, p. 1-16, 2002.

OGLIARI, A. et al. Projeto integrado de produtos: planejamento, concepção e modelagem. Barueri, SP: Editora Manole, 2008, 601 p.

PAULA, J. O.; MELLO, C. H. P. Seleção de um modelo de referencia PDP para uma empresa de autopeças através de um método de auxilio à decisão por múltiplos critérios. Produção, v. 23, n. 01, p. 144-156, 2013.

PUGH, S. Creating innovative products using total design: the living legacy of Stuart Pugh. Addinson Wesley. 1996, 544 p. 
ROZENFELD, H. et al. Gestão de desenvolvimento de produtos: uma referência para a melhoria do processo. São Paulo: Saraiva, 2006. 542p.

ROZENFELD, H. Modelo de referência para o desenvolvimento integrado de Produtos. In: ENEGEP, 17, 1996, Gramado. Anais... Gramado: ENEGEP, 1996.

ROZENFELD, H.; SILVA, S. Proposição de um modelo para avaliar a gestão do conhecimento no processo de desenvolvimento de produtos. Ciência da informação, v.36, n.1, 2007.

SALGADO, E. G. et al. Modelos de referência para desenvolvimento de produtos: classificação, análise e sugestões para pesquisas futuras. Revista Produção Online, v. 10, n. 04, p. 886-911, 2010.

SOUZA, V. M.. Desenvolvimento de Ferramenta para Avaliação de Projeto de Produto dom Fim de Vida Sustentável Baseada em Modelo Stage-Gate Aperfeiçoado com Abordagem Set-Based. 2012. Dissertação (Mestrado em Engenharia Mecânica e de Materiais), - PPGEM. Universidade Tecnológica Federal do Paraná, Curitiba, 2012. 118 p.

SUSMAN, G.I.: Integrating design and manufacturing for competitive advantage. New York: Oxford University Press, 1992, $320 \mathrm{p}$.

TAKAHASHI, S.; TAKAHASHI, V. P. Gestão de Inovação de produtos: estratégia, processo, organização e conhecimento. Rio de Janeiro: Campus, 2007.

THIOLlENT, M. Metodologia da pesquisa d -ação, 15 ed. São Paulo: Cortez, 2007.

VIEIRA, A. V. et al. Os benefícios da aplicação do projeto integrado no desenvolvimento de redutores planetários sob encomenda. In: SEPROSUL, 15, 2015 Anais... Sorocaba, p. 1-11, 2015.

VIEIRA, A. V. Modelo de referência para desenvolvimento de produtos mecânicos. Dissertação (Mestrado em Engenharia de Produção), Universidade Federal de São Carlos, Sorocaba, 2016. 88 p. 